\title{
A TERAPIA DE CRISE SEGUNDO ALFREDO MOFFATT: UMA PROPOSTA FENOMENOLÓGICO-EXISTENCIAL
}

\author{
The Crisis Therapy Second Alfredo Moffatt: a Phenomenological-existential Approach
}

La Terapia de Crisis Según Alfredo Moffatt: un Planteo Fenomenológico-existencial

Gustavo Alvarenga Oliveira Santos

\begin{abstract}
Resumo: Nesse artigo se apresenta alguns aspectos biográficos do psicólogo social argentino Alfredo Moffatt, importantes para a contextualização histórica de sua base teórica e conceitual, bem como de sua proposta de terapia de crise. Em um segundo momento aprofunda-se nos conceitos erigidos pelo autor que servem como fundamento para o conceito de crise, a existência humana como realidade temporal e espacial encontra ecos na fenomenologia de Husserl e em autor da tradição fenomenológico-existencial, que serão apontadas. Na terceira parte do texto é apresentado o modelo de terapia de crise do autor e os quatro passos sugeridos: contención, regresión, explicación e cambio. Esses passos geram atitudes terapêuticas distintas: empática, hermenêutica e proativa. Exemplifica-se seu uso no atendimento realizado pelo autor na tragédia da boate de Cromañon ocorrida no ano de 2004 em Buenos Aires que vitimou fatalmente 194 jovens. O texto se encerra com uma discussão sobre a relevância do trabalho de Moffatt para os atuais modelos de atendimento a crises psíquicas, assim como sua originalidade em termos sócios culturais.
\end{abstract}

Palavras-chave: Alfredo Moffatt; Temporalidade; Terapia de crise; Psicoterapia fenomenológico-existencial.

\begin{abstract}
This article presents some biographical aspects of Argentine social psychologist Alfredo Moffatt, important to the historical context of its theoretical and conceptual foundation as well as its proposal for crisis therapy. In a second step deepens the concepts erected by the author that serve as the foundation for the concept of crisis, human existence as temporal and spatial reality resonates in Husserl's phenomenology and autore the existential-phenomenological tradition, to be identified. The third session presents the author's crisis therapy model and the four suggested steps: contención, regression, explicación and cambio. These steps generate different therapeutic approaches: empathic, hermeneutics and proactive. An example is its use in the service provided by the author in the tragedy of Cromañon nightclub held in 2004 in Buenos Aires that killed 194 young. The text concludes with a discussion of the relevance of Moffatt's work to current models of care for mental crises, as well as its originality in terms cultural partners.
\end{abstract}

Keywords: Crisis Therapy, Alfredo Moffatt, Temporality, Phenomenological-existential psychotherapy.

Resumen: En este artículo presentase algunos rasgos biográficos del psicólogo social argentino Alfredo Moffatt, que son importantes para la contextualización histórica de su base teorica y conceptual, así como de su planteo de terapia de crisis. En un segundo momento profundizase los conceptos del autor que sirven como fundamentos para el concepto de crisis, la existencia humana concebida como realidad temporal y espacial resbala en la fenomenología de Husserl y en autores de la tradicción fenomenológico-existencial que serán señalados. En la tercera parte del texto presentase el modelo de terapia de crisis del autor y los cuatro pasos sugeridos: contención, regresión, explicación y cambio. Esos pasos generan actitudes terapéuticas distintas: empática, hermenéutica y proactiva. Ejemplificase su uso en el atendimiento realizado por el autor en la tragedia del boliche Cromañon que ocurrió en el año de 2004 en Buenos Aires, victimando fatalmente 194 jóvenes. El texto termina con una discusión respecto a la relevancia del trabajo de Moffatt para los actuales modelos de atendimiento a crisis psíquicas, asimismo señalase su originalidad sociocultural.

Palabras-clave: Alfredo Moffatt; Temporalidad; Terapia de crisis; Psicoterapia fenomenológico-existencial.

\section{Introdução}

O psicólogo social argentino Alfredo Moffatt, pese a divulgação massiva de sua obra na década de 80, principalmente entre os psicólogos sociais e comunitários, é um autor relativamente pouco conhecido pela nova geração. A associação de seu nome aos movimentos populares, principalmente da luta antimanicomial e da antipsiquiatria, velam suas bases teóricas e epistemológicas, pouco exploradas pela literatura psi. Isso posto, esse artigo visa demonstrar a proposta teórica e metodológica do autor para a terapia de crise, desvelando seus fundamentos fenomenológicos e existenciais, nem sempre explícitos ou referenciados. Diferente dos iniciadores das psicoterapias de inspiração fenomenológicas e existenciais, como Ludwig Binswanger ou Medard Boss, que explicitavam os achados filosóficos de Heidegger ou Husserl, mas consoante com a nova geração de terapeutas dessa linha como Ernesto Spinelli ou Emmy Van Deurzen da escola inglesa, as propostas teóricas de Moffatt trazem os pressupostos filosóficos de forma tácita, mas configuradas com vistas ao atendimento clínico. Isso, a nosso ver, não as faz me- 
nos rigorosas, pelo contrário, ao se atentarem ao contexto cultural de onde surgem, o modelo de terapia de crise moffattiano pode contribuir para um diálogo com os modelos vigentes no Brasil.

Dos modelos que se aproximam ao eixo epistemológico fenomenológico-existencial podemos citar os de inspiração humanista (Mahfoud, 2013), fenomenológico-existencial (Morato, H., Barreto, C., \& Nunes, 2012), ambos centrados no dispositivo do plantão psicológico como forma de acolhimento das emergências e crises pontuais. O modelo de plantão já é utilizado no Brasil desde a década de 80 e vem sendo utilizado em instituições como escolas, hospitais, delegacias, entre outros. Em geral, o atendimento é feito numa sala e segue um método clínico tradicional de fala e escuta.

Nos últimos anos, a proposta de Da Costa (2014), cuja inspiração teórica é interdisciplinar e se aproxima da fenomenologia, inova ao inaugurar um dispositivo de urgência psíquica para pacientes com sofrimentos de “tipo" psicótico, nos dizeres do autor. Esse se assemelha ao modelo de Moffatt que visa o atendimento de transtornos graves executando-o na própria comunidade dos pacientes atendidos. Moffatt criou dispositivos na própria comunidade e Da Costa (2014) após uma chamada telefônica se dirige a essa. Nesse sentido, ambos modelos também são de grande valia para o atendimento emergencial a grandes catástrofes. No nosso entender, um modelo de inspiração fenomenológico-existencial e que se adeque à realidade sócio-cultural latinoamericana justifica, a nosso ver, a importância do trabalho de Moffatt nos dias de hoje.

Nascido em Buenos Aires em 1934, filho de uma mãe alemã e um país inglês, Alfredo Moffatt formou-se em arquitetura pela Universidade de Buenos Aires e, segundo sua autobiografia, devido ao tratamento repressivo da psiquiatria da época a um primo que sofreu um surto psicótico, passa a se interessar pelo tratamento psiquiátrico e se torna psicólogo social. Sua experiência profissional se inicia sob a coordenação de Pichón Riviére no Hospital J.T Borda, subúrbio de Buenos Aires, de quem se torna discípulo e seguiu sendo um grande inspirador de sua obra teórica e modelo de atendimento. Assim seu fundamento teórico bebe de distintas fontes como a psicanálise, o psicodrama e, de forma especial, a fenomenologia-existencial de Jean Paul Sartre, que justifica o termo existencial como o nome que dá a seu modelo de terapia de crise. Sem embargo o autor nutre uma visão singular sobre a relação entre práxis e teoria, como afirma na introdução de sua obra Psicoterapia del Oprimido, segundo Moffatt (1974):

Una psicoterapia descolonizada que elabore sus modelos teóricos resolviendo la problemática real y concreta del país y no importe con sumiso respeto los modelos de pensamiento que resuelven y se adaptan a lejanos problemas sociales europeos. Acá aclaramos que no proponemos pelear con arcos y flechas, pues nos parece muy eficiente el "armamento" científico europeo-norteamericano (tan eficiente que con él nos sometieron); todo lo contrario, debemos aprender a usarlo bien, sólo que desde la perspectiva opuesta, esto es desde y con el pueblo. Para esto es necesaria la inversión de la relación teoría- práctica, pues consideramos que solo luego de una praxis es posible establecer una teoría. Si, por ejemplo, las teorías sobre el Complejo de Edipo de Freud explican las relaciones familiares en la Villa Miseria, la usaremos y si, por el contrario, comprobamos que la estructura matriarcal (común entre las familias pobres) lo vuelve inútil buscaremos otra. Esta inversión del orden entre la teoría y práctica va a impedir la principal patología de nuestros grupos intelectuales, que es la teorización sobre la teoría, lo cual crea un mundo cerrado sobre sí mismo y donde nada puede ser realmente demostrado ni negado pues todo llega a ser un enorme bosque de palabras que impide ver la realidad concreta que lo rodea. Con la teoría puede pasar lo que con los muebles viejos: se acumulan tanto que no nos permiten mover en el cuarto. Y la solución pensamos que es la misma: quedarse con lo necesario y tirar el resto. O también puede suceder (y de hecho así ocurre muchas veces) que se afila tanto el cuchillo que se gasta sin haberlo usado nunca”. (p. 3)

Sua experiência nas classes populares e sua articulação com a saúde mental é respaldado, em parte, por um dado importante de sua biografia. $\mathrm{O}$ autor recebeu uma bolsa de pesquisa para os EUA, onde viveu por dois anos, atuando no Brooklin State Hospital em Nova York, segundo Moffatt (2007b):

En Estados Unidos me sentí muy cómodo tal vez por el origen anglosajón de mi familia paterna... en el barrio que vivíamos había una calle que se llamaba Moffatt. Aprendí un inglés muy callejero, trabajaba con marginales, me encantaba. Era la época de los hippies aunque estaban ya cerca de la decadencia, corría el año setenta o setenta y uno. Absorbí todo ese mundo. (p. 11)

Já na Argentina, em 1971, inaugura o que considera sua primeira grande experiência comunitária e o início de sua obra, a comunidade terapêutica La Peña Carlos Gardel, no mesmo Hospital Borda, onde iniciou sua formação, segundo Moffatt (2007b):

La Peña dio lugar a muchas otras experiencias comunitarias, dio los grupos de mateadas, dio el Psicodrama en forma de teatro popular, dio cooperativas de trabajo y además el libro Psicoterapia del Oprimido. Muchos desarrollos que hice tienen origen en esa comunidad terapéutica. (p. 16) 
Sua experiência na fundação e aprimoramento dessa comunidade o fizeram um alvo do regime militar que via com desconfiança quaisquer grupos ou organizações populares. Nesse tempo, o sucesso de seu livro Psicoterapia do Oprimido no Brasil, possibilitou que fosse chamado a nosso país como conferencista e professor convidado em diferentes universidades e supervionasse atendimentos de saúde mental de distintos lugares. Nesse país se junta a Paulo Freire em conferencias e trabalhos comunitários, seu livro quase homônimo ao do educador brasileiro é reeditado nove vezes em português.

Quando a Argentina reabre à democracia e os trabalhos comunitários puderam ser feitos com mais liberdade, Alfredo cria o Bancaderos, um grupo de ajuda psicológica mútua que tinha como objetivo o atendimento às urgências psíquicas em uma zona popular e conturbada da cidade de Buenos Aires, o bairro Once, segundo Moffatt (2007b):

El Bancadero es una comunidad que fue amasada con mucho amor y responsabilidad científica. las fiestas, los grupos terapéuticos, los talleres de psicodrama, el teatro, el semillero de formación. Esta es una experiencia que fue repetida después y dio elementos para otras en Argentina siempre con el concepto de Primeros Auxilios Psicológicos de contención. (p. 26)

Desde El Bancadero, nota-se que o interesse do autor se desloca para o atendimento às urgências psíquicas, tema ao qual se dedica em pelo menos duas obras escritas e algumas centenas de palestras. Ademais, também promoveu a criação de comunidades autogestivas, como las Oyitas no bairro de Matanzas em Buenos Aires que visava o atendimento de crianças em situação vulnerável e a Cooperanza, conjunto de atividades que se realizam no Hospital Borda aos sábados, assim como a fundação da Escola de Psicologia Nacional de Pensamiento Nacional, que segundo Moffatt (2007b):

Hace casi diez años fundé la Escuela de Psicología Nacional de pensamiento nacional, por nación, como el lugar que uno nació... de pensamiento independiente, de acá... usando modelos europeos también, claro, pero llenándolos de contenido de acá... como hacen los europeos, hay psicología francesa, psicología inglesa. ¿Porqué nosotros no vamos a tener una psicología criolla? (p. 34)

Sua preocupação em desenvolver uma psicología criolla contribuiu para que em suas análises as formas populares e espontâneas de psicoterapia não científicas merecessem um destaque especial como se demonstra em seu interesse pelo tango, a umbanda brasileira, bem como os pastores e curandeiros populares. Para Moffatt (1974) o modo como os grupos humanos já se organizam para se psicoterapeutizar, desvela os aspectos sadios de uma cultura que precisariam ser resgatados nos trabalhos comunitários. Graças à sua proximidade com o popular e com as crises psíquicas oriundas das classes mais baixas, o autor se torna uma referência no atendimento das crises psíquicas de emergências sendo chamado para prestar atendimento em situações de grandes catástrofes, como no incêndio ocorrido na boate Cromañon em 2004 no mesmo bairro de Once em Buenos Aires, onde morreram 194 jovens. Nessa tragédia o autor pôde prestar um atendimento que se dava desde o primeiro acolhimento junto aos familiares, frente aos cadáveres dos jovens, até a elaboração do luto com a criação de um memorial. Atuação semelhante teve o autor no incêndio do supermercado Yuca Bolaños, ocorrido em Assunção no Paraguai, considerada a maior tragédia civil daquele país.

Sua experiência com o trabalho comunitário e o atendimento a crises psíquicas o motivaram a teorizar sobre o tema, sistematizando suas bases filosóficas e teóricas que nortearam sua prática. Assim os aspectos mais descritivos presentes em Psicoterapia do Oprimido, dão lugar a uma escrita mais teórica com clara inspiração filosófica, fazem parte desse conjunto: Terapia de Crise: teoria temporal do psiquismo de 2007 e Psicoterapia Existencial de 2011. Com base nessas obras podemos extrair uma proposta teórica e metodológica do atendimento das crises psíquicas inspiradas em uma proposta fenomenológico-existencial, em parte de clara inspiração sartreana, em outras partes de modo original tece, com base em sua experiência e leitura, compreensões advindas de múltiplas referencias epistemológicas, como já citamos.

Dito isso, este artigo visa explicitar o modelo de atendimento a crises psíquicas proposto pelo autor que parte de princípios fenomenológicos e existenciais, e que ademais pretende-se adequado às classes populares e à realidade sócio-cultural da América latina. Para tanto, demonstraremos primeiro as bases conceituais de que parte Moffatt e sua relação com a filosofia de Sartre, em outra parte, apresentaremos o modelo de atendimento a crises psíquicas defendido por ele e seu pano de fundo conceitual.

\section{A temporalidade como fundamento}

Moffatt (2011) entende que seu modelo de terapia rompe com a psicanálise freudiana ao substituir a centralidade da pulsão sexual pela temporalidade. Se o que estrutura o psiquismo para Freud era o temor à castração, já que a sexualidade era o grande tabu, para a terapia moffattiana, inspirada na concepção do dasein como ser-para-a-morte de Heidegger, a morte é o tema mais reprimido e central para a constituição da existência humana em particular. Sem embargo, o autor reconhece que, ter como princípio a castração ou a morte como elemento estruturante a priori, nada mais é que uma mudança de perspectiva que valorizaria mais o passado, no caso da psicanálise freudiana, ou o futuro, no caso dos existencialismos, no 
entanto, segundo o autor, a segunda perspectiva se adequa mais aos dias de hoje. A sociedade vitoriana do fim do século XIX a que pertencia Freud era mais estável que a Europa após a segunda guerra e a América Latina desde os tempos coloniais até os dias de hoje. Nesse sentido, segundo o autor o que é mais importante, para o nosso contexto é como viver, para que viver, que futuro teremos e não como adequamos ou não nossos impulsos sexuais às imposições sociais. Nesse sentido, o existencialismo de Sartre, centrado na noção de liberdade e projeto oferece um pressuposto epistemológico mais adequado para as terapias de hoje, segundo Moffatt (2011):

Nuestro modelo psíquico, que tuvo origen en la observación clínica, en el intento de resolver las crisis psicológicas, recibió el apoyo teórico del existencialismo, especialmente el sartreano, con el que convergió. (p. 26)

Além disso, segundo o autor, a época vitoriana na qual vivia Freud sobrevalorizava o passado, pois a parcela da sociedade atendida pelo pai da psicanálise apegava-se em demasia às tradições aristocráticas e burguesas. Por outro lado, na sociedade atual, sobretudo no contexto popular latinoamericano, a tradição perde seu peso e o indivíduo é chamado a responder pelo seu futuro e seu projeto de realização no mundo. Portanto, o contexto entre guerras no qual o existencialismo sartreano foi gestado é adequado à realidade social da América latina, na qual o existente é chamado a responder pelo seu futuro.

Sartre (1997) concebe o ser do homem como um serpara-si em contraposição a um ser-em-si. Isso quer dizer que no ser-humano o ser não tem identidade consigo mesmo, o homem é falta de ser, pois se encontra sempre em busca de uma apreensão de si, o homem deve ser o que é, ou seja, seu ser depende de um projeto de ser para algo. Esse movimento de não ser em si mesmo, mas buscar ser nos possibilita compreender o homem como liberdade pois o seu ser só se dá na medida em que ele mesmo se projeta. Por isso não há essência humana, pois nada o pode definir de antemão, antes que esse se apresente e se proponha.

Assim, desde o ponto de vista sartreano, o tempo não pode ser entendido como um ser- em-si, ou seja, que exista independente do homem, para Sartre (1997): "A Temporalidade não é, mas o para-si se temporaliza existindo" (p. 192). Portanto, tudo o que se pode afirmar sobre o tempo deve ter como ponto de partida o ser do homem que se projeta, ora como presença a si mesmo, presente; ora com o seu ser-sido, passado; ora como um projeto que se dirige ao aberto e vazio de si mesmo, futuro. $\mathrm{O}$ futuro, na concepção de Sartre, tem primazia sobre os demais êxtases temporais, na medida em que é nessa dimensão que o para-si determina a si mesmo como livre, deparando-se com sua indeterminação e podendo se projetar como um vir-a-ser.
Por isso, partindo desse ponto de vista, pode-se conceber o homem como um ser que temporaliza e é responsável por sua temporalização. Consoante a isso, segundo Moffatt (2011), o tempo é constituído pelo homem com base na percepção do antes e do depois, para o autor o que existe em si é o movimento do espaço, mas sua sucessão só pode ser constituída por um eu que se projeta imaginariamente sobre a realidade. Do ponto de vista moffatiano o tempo é uma atitude humana em relação ao mundo que tem como base uma percepção real. Nesse sentido Moffatt entende que a temporalidade é o alicerce do imaginário e da linguagem, leitura possível dentro de uma concepção sartreana, já que tanto a linguagem como o imaginário são atividades do para-si.

Como elemento central do ser, análogo à concepção de ser-para-si o autor propõe o conceito de Yo Soy, desde onde se constitui o tempo, dependendo de sua atitude frente ao real. O real é entendido como o espaço das relações sociais, sejam privadas e públicas, nesse sentido Moffatt também se remete a Sartre quando esse afirma que a identidade é uma resposta do outro. Portanto a dimensão de ser-para-o-outro é, para o nosso autor, a realidade, que por sua vez dá sustentação à identidade entendida como um Yo Soy. Esse se estruturaria horizontalmente no tempo, como um fluxo contínuo e cambiante de experiências e verticalmente no espaço, como bloco estável e real, conformada pela cultura e legitimada pelo olhar do outro.

Essa concepção servirá de base teórica para o modelo de atendimento às crises psíquicas esquematizada no seguinte quadro proposto por Moffatt (2011):

ESQUEMA EN CRUZ vínculos y temporalidad

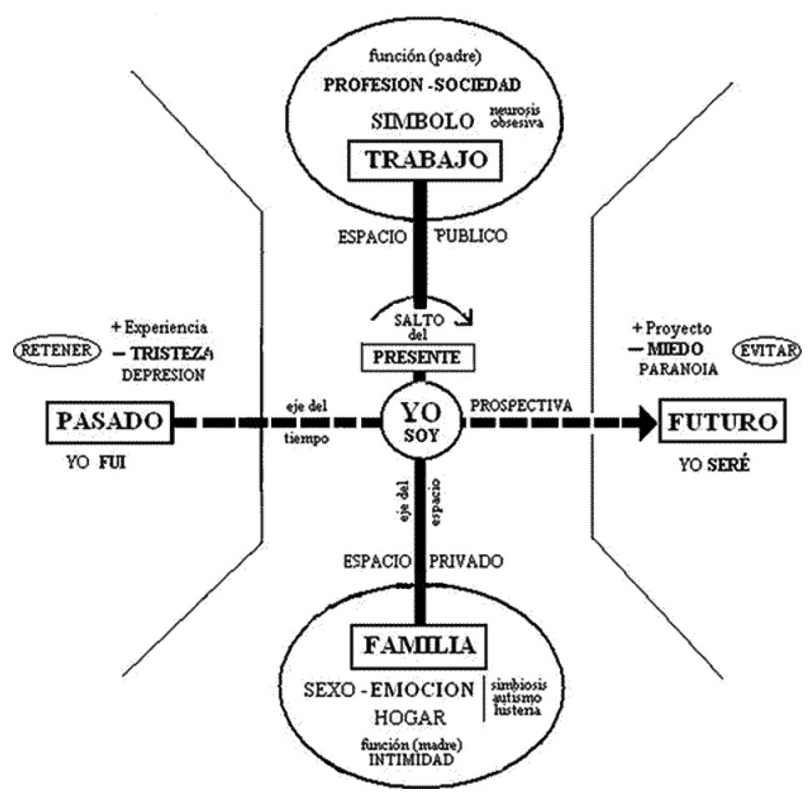

As vinculações com o mundo se dão nesse jogo temporo-espacial na qual o Ya Fui, representante do passado 
e o Yo Seré que representa o futuro, constituem a linha horizontal. Já a linha vertical representa o espaço que é dividido entre privado, representado pela família e público, representado pelo trabalho. Na interseção entre tempo e espaço está o Yo Soy, que no passado retém e no futuro se prospecta, se a retenção predomina isso pode conduzir a estados melancólicos por um excesso de Yo Fui, da mesma forma o deslocamento excessivo do Yo Soy para o Yo Seré pode conduzir aos estados ansiosos e paranóicos, já que o Yo Soy antecipa-se no que ainda não é. Em ambos estados, o tempo que é imaginário ocupa o espaço, o que ocasiona que cenas imaginárias invadam a percepção presente e real, por isso depressivo percebe o real em decorrência do que já foi, entendendo cenas reais com aspectos imaginários e o paranóico percebe o real em decorrência do que imagina que pode suceder.

Já o eixo do espaço serve ao mesmo tempo de base e ápice do Yo Soy, sua base é circunscrita nos espaços de intimidade, seu ápice, o espaço público. O intercâmbio entre esses dois espaços também se relaciona com as patologias típicas, quando um espaço prevalece sobre o outro e o Yo Soy se priva de algum deles. Assim, no caso da prevalência do espaço privado, as relações histéricas, tão bem descritas por Freud, que obedece à formula do Eu simulo ser, e no caso da prevalência do espaço público sobre o privado as neuroses obsessivas que obedece à formula do Eu devo.

Esse entendimento da relação do existente para com o Ser, encontra paralelos na psicopatologia fenomenológica clássica, como nos trabalhos de Von Gebsatell (1967), sobre o tempo na melancolia, para quem a melancolia é uma retenção do fluxo do tempo; e o trabalho de análise do caso Suzanne Urban de Ludwig Binswanger (1988), no qual a paciente, após ouvir o diagnóstico de que seu marido padecia de câncer, passa a desenvolver sintomas persecutórios de modo que o mundo "real" passa a ser visto como ameaçador. Outrossim, chama atenção a proximidade com a descrição topológica mais atual de Charbonneau (2010) que entende os modos patológicos da existência em relação ao posicionamento do Ser para com a existência, de modo que histeria é uma forma de ser abaixo de si, L'étre au deçà de soi, a melancolia uma forma do ser atrás de si L'étre en arrière de soi e a paranóia como ser acima de si, o que é análogo à proposta de Moffatt.

Pois bem, desde esse esquema que demonstra as formas como o ser se vincula no mundo no tempo e no espaço precisamos definir o que é Crise e como essa é entendida como fenômeno temporal. Se o tempo é uma atividade do para-si, constituído pelo Yo Soy, ele é ao mesmo tempo assimilação de recordações que é o passado e projeção das expectativas no futuro. As expectativas são criadas mais ou menos conforme o que determinado grupo cultural elege como ideias e projetos e quando não se cumprem,se instaura a crise que ameaça a existência do Yo Soy. Como afirma Moffatt (2007a):
La crisis se manifiesta por una experiencia de paralización de la continuidad del proceso de vida. De pronto nos sentimos confusos y solos, el futuro nos aparece vacío y el presente congelado. Si la intensidad de la perturbación, sea una crisis de crecimiento (evolutiva) o la consecuencia de un cambio imprevisto (traumática), aumenta, comenzamos a percibirnos como "otro", es decir, tenemos una experiencia de despersonalización. Esto provoca una discontinuidad en la percepción de nuestra vida como una historia coherente, organizada como sucesión en la que cada una de las etapas es consecuencia de la anterior. Por lo demás, todos tenemos experiencias de las crisis psicológicas, pues forman parte del recorrido por diversas etapas llamado vivir, o más exactamente existir. Para que una situación produzca una crisis, más importante que el nivel de traumatismo sufrido por el paciente es lo inesperado de la nueva situación que se le exige vivir, la que sentirá como "irreal” y experimentará fuera de lo que está sucediendo. Diríamos que sólo es real lo que se espera, lo que fue concebible antes como posibilidad en la fantasía de futuro. Por eso se dice que esto o lo otro no estaba previsto (previsto), esto es, no estaba visto de antemano y cuando las circunstancias nos colocan dentro de un personaje que nunca habíamos anticipado, el de huérfano, viudo, adulto, exiliado, etc., puede sobrevenir el desconcierto, la crisis. (p. 6)

Moffatt sugere assim que a patologia básica da qual derivam todas as outras, tal como demonstrado no esquema gráfico apresentado é a dissolução do Yo Soy. Esse é mantido no tempo pela projeção imaginária do futuro e a assimilação do passado, assim como no espaço em sua ubiquação no mundo das relações privadas e públicas. Sua existência se vê ameaçada quando as expectativas projetadas ou os espaços imaginados se rompem de tal maneira que sua existência é ameaçada. No aspecto cultural, o autor defende que as culturas populares podem ser mais resilientes a algumas rupturas, dada a falta de sedimentação de tradições, pois não investem tanto em um futuro imaginado, estando assim mais dispostas à morte e à finitude, enquanto as classes burguesas tendem a negar os ciclos vitais com a expectativa idealizada do futuro que nega a morte acabando por negar a própria vida. Segundo Moffatt (2011):

En síntesis, lo que proponemos es que hay una patogenia última que está por debajo, y es más arcaica que el trauma básico freudiano (la represión de la sexualidad, especialmente del incesto). Esta, es la posibilidad de desaparición del último reducto del yo, de esa porción de nosotros con la que íntimamente nos auto percibimos, y que llamamos el núcleo del yo (el sí mismo). Esto llevaría a la desaparición del último testigo de nosotros mismos, la disolución de nuestro último y más íntimo diálogo. Por esto las crisis son más 
probables y catastróficas en subculturas con defensas obsesivas (como por ejemplo, la clase media), que niegan el tiempo y la finitud, que en las subculturas con más aceptación del ciclo vital vida-muerte (como en la clase rural, la cultura criolla). (p. 45)

A crise é rompimento na continuidade do tempo e conseqüente desfacelamento da posição do Yo Soy no espaço, quando isso ocorre o Yo Soy pode se defender criando uma cena imaginária em um espaço real, o que pode ocorrer tanto nas projeções neuróticas como nos delírios. Assim o tempo tenta suplantar o espaço, ou seja a realidade psíquica tenta suprir a carência de realidade do espaço real que, dado o seu rompimento, é vivido como uma sensação de irrealidade. Esse estado nos lembra a conceituação de Blackenburgh (2014) sobre a perda da evidência natural extraído do caso Anne, comum aos quadros esquizofrênicos. Para esse autor, a perda da evidência natural, diz da perda das habitualidades comuns à vida e que foram sedimentadas no tempo, no estado esquizofrênico o mundo parece irreal pois tudo precisa ser reconstituído já que o tempo perde fluidez o que leva o paciente a suplantar esse vazio criando o delírio.

Moffatt entende que existem três formas de sair do circuito do tempo: o surto psicótico, o uso de algumas substâncias psicodélicas como o LSD e a meditação zen budista. No entanto, o autor adverte que tanto na arte, como na meditação e no uso drogas psicodélicas de forma controlada, pode-se sair do circuito mundano, mas há a possibilidade de voltar ao mundo dos outros, enquanto que nas crises psicóticas ou extremas é necessário um outro disposto a ressoar a existência de quem sofre para trazê-lo de volta ao mundo compartilhado, esse outro pode ser um terapeuta que deve, segundo Moffatt (2007a):

(...) meterse en el profundo pozo donde está el paciente, pero con una soga (la soga es el método o la técnica) y entonces ayudarlo a subir, en lugar de gritarle desde arriba: "salga del pozo, que afuera brilla el sol..." La primera etapa de contención es, entonces, la resonancia emocional, y se llama empatía. Es el momento de la identificación con el otro, para que el otro se sienta que uno está resonando con él. Uno se conmueve, se pone en el lugar del otro. Si el otro tiene miedo, uno evoca sus propios miedos para comprender los miedos del otro, y si está triste, las propias tristezas. (p. 64)

A empatia, entendida por Moffatt como um deslocamento do Yo Soy so modo de ser do outro, é base para o atendimento que procura resgatar o paciente do fora do circuito do tempo para a reconstituição de sua vida com os outros no mundo empírico. Muitas vezes incapacitado de voltar à vida comum, esse paciente necessita dessa corda possibilitada pelo terapeuta, veremos em detalhe o modelo moffattiano de atendimento em crise.

\section{Modelo de atendimento à crise psíquica}

Moffat (2007a) estabelece três momentos do atendimento ao paciente em crise psíquica: a) contención, b) regresión, c) explicación, d) cambio. O primeiro já adiantado acima trata-se da atitude do terapeuta de empatia e implicação para com o mundo do outro, no sentido de acolher a experiência de crise. Isso possibilita que o paciente recupere a ressonância de que existe no mundo compartilhado com os outros, como Mit-Dasein e dessa forma retome à linguagem e ao tempo. Ao recuperar o tempo, ele pode se abrir e recordar a experiência traumática remontando culturalmente um fato que o tirou do circuito do Yo Soy, ou seja, pode contar e recontar essa experiência até que ela ganhe realidade no tempo-espaço compartilhado e, por conseguinte, para si-mesmo como ser-no-mundo, sendo essa a etapa da regresión. A terceira etapa consiste em um trabalho mais ativo do terapeuta de, junto ao paciente, interpretar e dar um sentido existencial ao ocorrido, embora esse a princípio pareça não ter sentido algum. Essa etapa é muito importante, pois prepara a ultima que é a do cambio, que é a reconstrução do projeto existencial do paciente na sua realidade cultural.

É desejável que esse trabalho ocorra mesclando tempo e espaço, ou seja, elementos da realidade percebida e da realidade imaginada. Portanto, torna-se fundamental o encontro do terapeuta com o paciente através da palavra, pois essa reconfigura o tempo que foi rompido e está paralisado, mas é igualmente necessário devolver a capacidade do paciente de responder à realidade através de sua reinserção nos espaços públicos e privados. Sobre esse último, não basta apenas a verbalização terapêutica, mas também a dramatização com simulações de ações práticas, bem como a execução das próprias ações de mudança acompanhadas ou supervisionadas com o terapeuta. Assim, o atendimento se dá desde o acolhimento, que propicia uma catarse, verbalização e o retorno à cena traumática; a compreensão da situação, através do sentido existencial que essa tem para o existente e, por fim, uma ação concreta no mundo. Logo após a tragédia na boate Cromañon, Moffatt conta que se posicionava perto dos corpos das vítimas aguardando os familiares, quando chegavam e se deparavam com o corpo do ente morto, o silêncio e o acolhimento, em forma de abraço, serviam como o momento do acolhimento. Esse abraço também prosseguia quando o paciente era convidado a abraçar um almofadão com o qual podiam ficar o tempo que achasse necessário. Essa técnica foi chamada pelo autor de maternagem. A ideia é que, regredindo à vivencia de acolhida materna, através do abraço no almofadão, os pacientes encontrariam um forte recurso que lhes devolveriam o senso de Yo Soy, já que esse o remete, ao menos experiencialmente ao protótipo de todas as relações intersubjetivas, a mãe-bebê. Esse contato silencioso, sem palavras, aos poucos levava à catarse e os pacientes poderiam então se expressar sobre o ocorrido, 
inaugurando a fase de regressão, pois na primeira fase devido ao choque iminente, a palavra falta.

A terceira fase, explicação, no caso de Cromañon, foi feita através de oficinas que possibilitaram a fala e a escuta sobre a experiência vivenciada, nesse sentido também foram propostos exercícios de sociodrama, como um baile onde os pais e familiares puderam rememorar o sentido das músicas e da diversão para os seus filhos e a construção de um memorial em homenagem a eles, que existe até os dias de hoje na Plaza Miserere, no centro de Buenos Aires. A quarta fase, cambio, foi também acompanhada por oficinas e ajuda na reinserção laboral e estudantil dos familiares enlutados.

No exemplo acima, vimos como os quatro passos são modelos a seguir que vão se modelando à situação e se somando a técnicas diversas de acordo com a natureza do evento traumático e do contexto de atendimento. No caso da tragédia na boate Cromañon, Moffatt e sua equipe atenderam as pessoas enlutadas, desde instantes após o evento, até anos após o ocorrido, em um trabalho que variou atendimento individual, em grupo, técnicas de dramatização, sociodrama e trabalhos comunitários.

Do nosso ponto de vista, assinalamos como três as atitudes terapêuticas embasadas no modelo proposto por Moffatt de atendimento às crises: a empática, para as etapas um e dois, ou seja, contención e regresión, pois essas permitem confiança e segurança para que o paciente expresse intersubjetivamente o evento traumático. A hermenêutica, no cumprimento da etapa 3, que é da explicación, que propõe reordenar os sentidos apagados e rotos da vida do paciente após o evento traumático, requer uma atitude interpretativa e construtiva que vai desde as cenas traumáticas como parte, até o sentido total da existência do sujeito como um todo, e nesse círculo o ajuda a reconstruir os sentidos; e a proativa, na qual o terapeuta se engaja com o paciente na mudança construtiva de sua realidade. Do lado do paciente, o autor propõe que são três as etapas pelas quais passa um paciente após um evento traumático, a do choque psicológico, que é a sensação de vazio, como perda provisória do Yo Soy. De modo similar ao surto psicótico, essa etapa só pode ser acompanhada em silêncio, já a segunda etapa, é conhecida como diálogo de despedida, na qual o paciente começa a tecer um diálogo interno sobre o evento ocorrido, na tentativa de retomar o sentido do Yo Soy. A terceira etapa é conhecida como recriação da vida cotidiana, que é quando o paciente pode se mostrar disposto a recriar hábitos e sentidos perdidos após o evento traumático.

A compreensão do trauma como ruptura do tempo e instaurador da crise psíquica é análogo ao que ocorre nos surtos psicóticos, que o modelo de atendimento de crise moffattiano também se presta a trabalhar. Nesse a habilidade do terapeuta consiste em entrar na cena do delírio ajudando, com sua ressonância empática, a reconstruí-lo no sentido intersubjetivo até que ele perca sua força metafórica e o paciente consiga regredir a seu trauma gerador. Segundo Moffatt (2011) essa atitude requer do terapeuta habilidade e capacidade de reconhecer seu núcleo psicótico para ter segurança e versatilidade para entrar e sair, assim como reconhecer os personagens na cena do delírio e se inserir como um deles. $\mathrm{O}$ uso de elementos originados do psicodrama, combinados com técnicas de ressonância subjetiva, como o abraço ou o espelhamento, podem ajudar na realização na primeira etapa de contención. Segundo os ensinamentos de Pichon Riviére seguidos por Moffatt, todo delírio é uma verdade, uma metáfora de uma cena esquecida, por isso podemos ajudar o paciente, talvez não a recordar, mas a reconstruir seu sentido.

Independente de qual crise nos propomos a tratar, Moffatt (2007a) alerta que essa deve produzir não apenas mudanças na captação de seu sentido, mas também e sobretudo na realidade no entorno do paciente. De forma provocativa o autor sugere que toda terapia deve acabar em uma terapia familiar, de modo a apresentar a circunscrever o novo membro modificado e testá-lo frente a seus projetos e mudanças. $\mathrm{O}$ autor adverte para o risco que a terapia se esvaia apenas pela palavra, detendo-se na fase de explicación, não avançando até a fase do cambio. Esse processo, último da terapia de crise, deve ser cuidadoso e paulatino, mas não deve se furtar em intervir na realidade espacial, ou seja, o espaço público e privado do paciente, segundo Moffatt (2007a):

La etapa del cambio efectivo es sumamente delicada, pues en ella es donde se da el peligro de que el paciente se desconozca, de que tenga sentimientos de despersonalización. Curarse en la vida real resulta muy angustiante, pues significa realmente ser otro, "el curado”, y a nadie le gusta ser otro. Por esto el proceso terapéutico requiere cierto tiempo, debe ir de un paso al siguiente sin precipitaciones. Es posible acrecentar su eficacia y acelerar el proceso, pero nunca más allá de lo que admita la capacidad de transformación que tenga el paciente, aunque ésta se dé en la dirección que él requiere, esto es, de la curación. (p. 79)

Entendemos que esse é um diferencial interessante da proposta do autor pois, ao nosso ver, essa proposta vai além dos modelos existenciais apenas verbais que se mantém ainda presos ao modelo clássico da psicanálise, utilizando como critério de alta, apenas o trato no contrato verbal. Moffatt, nesse sentido deixa mostrar suas influências provindas da gestalt-terapia e do psicodrama entendendo o mundo da vida também como cenário composto por atores e a mudança como algo que ocorre, sobretudo, no mundo concreto. 


\section{Considerações finais}

As propostas de Alfredo Moffatt para a terapia de crise são bem vindas ao contexto brasileiro onde os atendimentos desse tipo não são ainda muito realizadas e, segundo nosso ponto de vista, muito menos do necessário frente às demandas sociais. Nesse sentido, a obra do autor, além de oferecer um modelo de atendimento epistemologicamente referenciado como fenomenológico-existencial, atenta-se para as especificidades culturais do contexto latino-americano que tem como marca a profunda desigualdade social e o massacre cultural promovido pelas classes dominantes.

Assim, em vistas a um trabalho comunitário o autor propõe recuperar a parte sana das comunidades, que para ele significaria rememorar os aspectos esquecidos e potenciais das culturas originárias que estão na memória, mas que, em consequência das rupturas sócio-culturais, acabam por retirar o sentido de um Yo Soy, acabando por gerar um eterno presente cíclico que não sustem um futuro. Esse é o cenário comum, destacado pelo autor, como típico das populações mais marginadas e excluídas na sociedade latinoamericana. Portanto, possibilitar que as comunidades recordem seu passado, reconstruam o sentido de seu existir e prospectem um futuro é também parte de um trabalho terapêutico que não deve se bastar no individual, mas ir ao encontro do sofrimento em sua base de origem que são os grupos e agrupamentos sociais.

Moffatt tem muito a dizer para os que realizam trabalhos em psicologia social, preventiva e atendimento em crises e que se utilizam de modelos teóricos importados e muitas vezes isolados do nosso contexto sócio-cultural. Salvo as diferenças culturais entre Brasil e Argentina, nos une a relação opressora entre a cultura dominante de base européia e os povos originários, escravizados e massacrados física e espiritualmente. Essa relação tem conseqüências sociais, culturais e psíquicas importantes, visíveis no atendimento em saúde mental, mas pouco consideradas do ponto de vista teórico e epistemológico. Enquanto herdeiros de uma tradição européia, sofremos os efeitos da colonização do saber, nesse sentido ao observar uma criança utilizando o material didático concebido pelo ministério da educação argentino Moffatt (2011) tece a seguinte observação:

Un niño de rasgos indígenas estaba mirando una ilustración en su libro de lectura, era la imagen de un chico rubio jugando con una ardilla... y el changuito tenía de mascota un peludo y vi que él se dio cuenta que no existía... el verdadero alumno era el rubio con la ardillita. (p. 123)

Da mesma forma, o papel transformador da prática psi deve vislumbrar ações que transcendam o caráter individual e que sejam críticos aos modelos impostos. Es- sa crítica não deve estar restrita ao campo da psicologia social, pois na medida em que o profissional psi se inclui nas políticas públicas de atendimento a populações vulneráveis sua clínica é todo o tempo interrogada. Portanto, defendemos que a questão cultural e social é uma questão de atendimento psicoterápico, uma vez que o lugar de inserção da práxis clínica não ocorre fora do circuito sócio-cultural no qual está inserido.

Moffatt nos brinda um modelo para o tratamento das crises e urgências psíquicas embasadas filosoficamente e epistemologicamente, situadas e versátil do ponto de vista técnico e metodológico. $\mathrm{O}$ artigo cumpre seu objetivo ao apresentar essa proposta e provoca os profissionais envolvidos nessa modalidade de atendimento ao diálogo com essa perspectiva. As referencias epistemológicas dos atendimentos de crise são vários, e, a nosso ver, esse é mais um que pode vir a se somar frente à complexa tarefa de compreender e intervir adequadamente nas crises e emergências psíquicas.

\section{Referencias}

Binswanger, L. (1988) Le case Suzanne Urban: etude sur la szichizophrénie. Trad. J. Verdeaux. Saint-Pierre-de-Salerme: Gérard Monfort.

Blankenburg, W. (2014). La perdida de la evidencia natural: una contribución a la psicopatología de la esquizofrenia. Trad. Otto Dorr y Elvira Edwards. Santiago de Chile: Ediciones UDP.

Charbonneau, G. (2010). Introduction à la psychopathologie phenomenologique. Tome I. Paris: Fédition.

Da Costa, I. (2014). Sofrimento Humano, crise psíquica e cuidado: dimensões do sofrimento e do cuidado humano na contemporaneidade. Brasília: Editora UNB.

Mahfoud, M. (2013). Desafios sempre renovados: plantão psicológico. Em M. A. Tassinari, A. P. S. Cordeiro, \& W. T. Durange (Orgs.). Revisitando o plantão psicológico centrado na pessoa (pp. 33-50). Curitiba, PR: CRV.

Moffatt, A. (1974). Psicoterapia del oprimido. Buenos Aires: Editorial Humanitas.

Moffatt, A. (2007a). Terapia de crisis: la emergência psicológica. Buenos Aires: Edición Bancavida.

Moffatt, A. (2007b). Vida de Moffatt. Disponível em: <www.alfredomoffatt.com.ar>.

Moffatt, A. (2011). Psicoterapia existencial. Buenos Aires: Esperanza.

Morato, H., Barreto, C., \& Nunes, A. (Orgs.) (2012). Aconselhamento psicológico numa perspectiva fenomenológica existencial: uma introdução. Rio de Janeiro: Guanabara Koogan.

Sartre, J. P. (1997). O Ser e o Nada: ensaio de ontologia fenomenológica. Petrópolis: Ed. Vozes. 
Von Gebsatell, V. E. (1967). El mundo de los compulsivos. In: Rollo May; Ernest Angel; Herni Ellenberger (Eds.). Existencia: nueva dimension en psiquiatria y psicologia (p. 212-231). Madrid: Gredos.

Gustavo Alvarenga Oliveira Santos - Possui graduação em Psicologia pelo Centro Universitário Newton Paiva (2001) e Mestrado em Psicologia Clínica pela Pontifícia Universidade Católica de Campinas (2003). Professor Assistente da Universidade Federal do Triângulo, atualmente cursa Doutorado na Universidade de Buenos Aires. Endereço Institucional: Universidade Federal do Triângulo Mineiro, Pro-Reitoria de Ensino - Psicologia. Rua Getúlio Guaritá, 159. Nossa Senhora da Abadia. CEP: 38025-440 - Uberaba, MG. E-mail: gustalvarenga@hotmail.com

Recebido em 01.10.15

Primeira Decisão Editorial em 03.03.16 Aceito em 04.06.16 